\title{
The predictive role of individual differences of the work performance of Lithuanian driving examiners
}

\author{
Auksė Endriulaitienè, Laura Šeibokaitè, Rasa Markšaitytè, \\ Kristina Žardeckaitè-Matulaitiené \\ Vytautas Magnus University, Kaunas, Lithuania
}

\begin{abstract}
Driver examiners are one of the first traffic safety agents as they ensure that candidates with bad skills do not participate in the traffic as licensed drivers. The aim of this study is to evaluate the role of individual differences for the occupational performance of driving examiners in Lithuania. 103 male examiners and 10 their supervisors participated in the study. Examiners filled in the self-report questionnaires: NEO-PI-R personality questionnaire, the scale of attitudes towards traffic safety, and situational judgement test assessing communication competence. Job performance rates were obtained from supervisors using the routine procedure implemented in the organization. Examiners rated by supervisors as more proficient are those who have higher conscientiousness, agreeableness, openness to experience, extraversion and lower neuroticism as well as high communication competence and more positive attitude towards traffic safety. Communication competence was the only significant predictor of better job performance of driver examiners when controlling for interaction between tested variables. Although the data allowed to distinguish psychological characteristics of examiners who were rated as performing better at their work, the predictive role of individual differences was modest. Other research strategies and variables should be applied in order to reach more comprehensive results in this field.
\end{abstract}

KEYWORDS: driving examiners, job performance, personality traits, attitudes towards traffic safety, communication competence.

\section{INTRODUCTION}

The occupation of driving examiners might be the one that has interdisciplinary importance and broader implications for public health. Traffic safety con- tributions, involving holistic efforts in multiple sectors, e.g., police, engineering, health, education, and licensing are one of the priorities of the newly adopted 2030 Agenda for Sustainable Development of the United Nations (United Nations, 2015; WHO, 2018). Driver examiners might be one of the first traffic safety agents as they ensure that candidates with bad skills do not participate in the traffic as licensed drivers. Examiners might contribute to the safety on the road and public health by performing their job tasks in the efficient way. Therefore, the assurance of high-quality examining procedures might be one of the countermeasures of risk taking on the road and crash rates in any country (International commission for driver testing CIECA, Twisk \& Stacey, 2007). Surprisingly the research on job performance of driver examiner, selection issues and its antecedents in traffic safety as well as in occupational psychology literature is almost non-existent neither in Lithuania nor in all over the world.

The job of a driving examiner might be perceived as difficult, stressful, demanding high responsibility and ethical behaviour (Driver and Vehicle Standards Agency, DVSA, 2017, Parkes et al., 1986). The examiner must perform an objective evaluation of examinee's driving skills in a short period of time (this is task performance according to Borman \& Motowildo, 1997). Usually they have to deal with clients who are in a state of big stress. Therefore, the examiner has to show the ability to support the examinee and to create an atmosphere in order to ensure the demonstration of examinee's skills even in the stressful situation. The examiner has to stay calm in situations where driver-candidates act hostile, if they treat examiner's decision or examining procedure as unfair. Finally, the examiner must demonstrate ethical and safe behaviour in order to maintain the reputation of fair and transparent institution that he/ she represents. These later behaviours might be classified as contextual per- 
formance of the profession that might be related to different factors (Borman \& Motowildo, 1997; Jaakson, Vadi, \& Baumane-Vìtolina, 2018). Still, there is no clear answer how such job proficiency might be achieved and who are those people who qualify best for this job. Deeper knowledge would be helpful for the development of evidence based recruitment and selection procedures of driving examiners.

Many countries in Europe have specific requirements to the candidates to apply for position of a driving examiner and they are quite similar across different institutions. Typically they include minimal age and education, driving licence category, good skills of driving, absence of recent traffic offences. Some countries report psychological fit as an additional requirement (International commission for driver testing CIECA, 2017). Still, all requirements for driving examiners are mostly selected on common sense justification and it is difficult to predict if candidate meeting these requirements will be proficient driver examiner in the future. There is no evidence-based knowledge what personal characteristics and skills driving examiners have to possess. Based on the literature in organizational psychology on personnel selection and recruitment procedures for other customer-oriented occupations, it might be expected that psychological attributes add to the job proficiency among driver examiners. Weldon, Fletcher, \& MacIver (2017), Teodorescu, Furnham, \& MacRae (2017) state that individual psychological characteristics have predictive validity for the success at work. Extensive research in personnel psychology have found that personality traits, selfefficacy, stress tolerance, emotional intelligence, values, communication skills or cognitive abilities are related to job performance among employees of different occupations (Ones, Dilchert, Viswesvaran, \& Judge, 2007; Neal, Yeo, Koy, \& Xiao, 2012; Bedwell, Fiore, \& Salas, 2011; Sjöberg, Sjöberg, Näswall, \& Sverke, 2012; Rode et al., 2006; Carraher, 2011). Thus, it is reasonable to assume that personality traits, interpersonal skills and jobrelated attitudes would be important for proper driving examination as well. Based on the literature, the proper job performance of driving examiner here is defined as employee behaviour quality at work rated by his/her supervisor (Joseph, Jin, Newman, \& O'Boyle, 2015). Supervisor ratings of performance might be sometimes treated as biased, still such strategy is usual in research as results reveal that subjective performance ratings are relat- ed to objective work results (Chamorro-Premuzic \& Furnham, 2010).

The Big Five Model of personality traits is widely used in international personnel selection and recruitment research and practice as well as in other fields of job performance management (Barrick, Mount, \& Judge, 2001; Schmitt, 2014). Repeated data support the conclusion that personality predicts job performance (Rothstein \& Goffin, 2006; Judge \& Zapata, 2014). Research results consistently show that higher levels of conscientiousness predict better job performance across all occupations (Lang, Zettler, Ewan, \& Hulsheger, 2012; Neal et al., 2012; Sjöberg et al., 2012; Teodorescu et al., 2017). The role of other traits of Big Five in occupational success is more controversial. Higher emotional stability and agreeableness are related to better job performance among policemen, military and other law enforcement employees (Ones, Dilchert, Viswesvaran, \& Judge, 2007; Bilgiç \& Sümer, 2009). Positive correlation between extraversion and occupational success is reported in Gilar, de Haro, \& Castejon (2015) and Weldon et al. (2017). Openness to experience is a good predictor of job success in the areas where high uncertainty and innovative environment is prominent (Bilgiç and Sümer, 2009; Neal et al., 2012). Despite significant correlations in previous studies, agreeableness and neuroticism failed to predict job performance in some samples (Gilar, de Haro, \& Castejon, 2015; Sjöberg et al., 2012; Neal et al., 2012). However, Ones, Dilchert, Viswesvaran, \& Judge (2007) found that all five personality traits contribute to the explanation of job efficiency among service providing employees. As the job of driving examiners is of social nature which involves constant interaction with clients, in the current study it is hypothesised that higher conscientiousness, emotional stability, agreeableness, openness to experience, and extraversion are related to better performance at their work.

Despite the prominent role of personality traits in occupational settings, some authors argue that their explanatory value and incremental validity in job success prediction can be modest (Neal et al., 2012; Chamorro-Premuzic \& Furnham, 2010). They encourage to look for other more specific and contextualized characteristics important for work achievements and success. Lievens \& Sackett (2012) found that the communication skills of job candidates at the selection stage was related to their work proficiency seven and nine years later. Bedwell et al. (2011) confirmed that interpersonal skills are very important 
for the efficient work of managers, service sector employees, sellers, teachers, etc. The current study addresses communication competence of driver examiners as potentially informative attribute of their work behaviour. Interactions with driver candidates during examining procedure require some specific interpersonal skills described in their job specification, like verbal communication skills, empathy, emotional self-regulation, coping with stress, flexibility in social interactions, and support. Therefore, it is hypothesized that superior communication competence is associated to better occupational performance of driving examiners.

Even more contextualized variable in driving context might be the risk taking attitudes of examiners. Usually work-related attitudes, like job commitment, job satisfaction or work engagement, are investigated in the employee selection and work performance context (Salanova, Llorens, \& Schaufeli, 2011; Hashimoto, Andreassi, Nakata, \& Artes, 2016; Zhong, Wayne, \& Liden, 2016; Schrock, Hughes, Fu, Richards, \& Jones, 2016; LazauskaiteZabielske, Urbanaviciute, \& Rekasiute Balsiene, 2018). Still, taking into account the judgemental nature of examining procedure, social cognition and decision-making biases of driver examiners might be important in the quality of driving candidate's evaluation during exam. Previous literature proposed that false consensus (or self-reference) bias might be the most relevant in this case. Under the influence of this bias, people rely on their own attitudes when judge behaviour of others (Beshai, Prentice, Swan, \& Dobson, 2015; Perugini, Zogmaister, Richetin, Prestwich, \& Hurling, 2013). It could be expected that driving examiners who accept risk taking on the road will be more unconsciously indulgent to the examinees with similar risk proneness. Based on this it is hypothesized that examiners with riskier driving attitudes will be rated as less proficient employees by their supervisors.

It has to be noted that cognitive abilities are typically addressed in the selection and recruitment literature as the most predictive indicator of work success (Chamorro-Premuzic \& Furnham, 2010; Schmitt, 2014; Sjöberg et al., 2012; Higgins, Peterson, Pihl, \& Lee, 2007). Nevertheless, this study did not include the measurement of cognitive abilities of driving examiners for several reasons. The formal requirements in job descriptions for this occupation ensure the necessary level of cognitive functioning. It is presumed that college degree warrants the proper quality of job performance. Additional testing of general mental abilities would not be cost-efficient. Also Lievens \& Sackett (2012) argued that communication skills were more important for job success than cognitive abilities. Finally, the procedure of becoming the driving examiner in Lithuania involves the threemonths learning period to screen for candidates with sufficient cognitive skills necessary for employment. In order to minimize the potential impact of cognitive factors when analysing job performance of driving examiners, the education level was controlled as the distal covariate of cognitive abilities.

In summary, the main aim of this paper is to empirically evaluate the role of individual differences (personality traits, communication competence, and risk attitudes on the road) for the occupational performance of driving examiners in Lithuania. The question how personality traits, communication competence and risk attitudes contribute to the quality of examining is investigated. It is hypothesized that controlling for education higher conscientiousness, emotional stability, agreeableness, openness to experience, and extraversion is related to better job performance (H1), as well as better communication competence and less positive attitudes towards traffic risk contribute to more proficient job performance $(\mathrm{H} 2)$.

\section{METHOD}

\subsection{Sample}

The driving examiners were approached in all regions of Lithuania where driving licensing is proceeded at the state enterprise "Regitra" (the only organization in the country that is responsible for drivers' licensing). 103 examiners participated in the current study (this constitute 93 percent of all working examiners at the moment). All participants were males, mean age 49.5 years $(\mathrm{SD}=9.3)$, mean work experience as examiner 10.2 years $(S D=2.5)$. Half of the sample (54.4 percent) was representing three largest cities of Lithuania, 45.6 percent of examiners worked in smaller towns. 10 supervisors rated from three to twenty examiners depending on the size of work unit in the organization.

\subsection{Assessment instruments}

Self-report questionnaires were used for the assessment of individual differences. All instruments were 
administered in Lithuanian. Personality traits were measured with the help of 240-item NEO-PI-R personality questionnaire (Costa \& McCrae, 1992; Lithuanian version was standardized by Bagdonas $\&$ Kairys, 2012). This questionnaire has been adapted for the use in Lithuania, standardized norms for evaluating respondents' scores in different settings are established and published. The internal consistency of scales was high in this study - Cronbach alpha for neuroticism was .88 , Cronbach alpha for extraversion was .82 , Cronbach alpha for conscientiousness was .89 , Cronbach alpha for agreeableness was .82, Cronbach alpha for openness to experience was .85. The higher score on each scale indicated a higher level of each trait.

Attitudes towards traffic safety were assessed by 16-item scale (Iversen \& Rundmo, 2004). The scale was translated into Lithuanian using forward - back procedure by the authors and used in earlier studies (Authors, 2016). All items were scored on five-point Likert scale, ranging from 1 (strongly disagree) to 5 (strongly agree). The general mean value of the scale was used in the analyses, where higher score indicated more preference for risk-taking on the road (Cronbach alpha was .66). Item examples of this scale: "It is acceptable to drive when traffic lights shift from yellow to red", "Traffic rules are often too complicated to be carried out in practice".

Communication competence was measured with the help of Situational judgement test (SJT) for driver examiners developed for the purposes of the current study. We used 10 hypothetical job-relevant situations assessing diverse communication skills, like flexibility in social interactions, conflict resolution, coping with stress, showing support for other person (empathic concern). Each situation provided five response options for the respondent, who has been instructed to choose one course of action matching the mostly probable respondent's behaviour in such situation. The answers were coded as "true/ false" depending on the scoring key of SJT. The overall sum of true answers of each participant (maximum 10) was used in later analysis (Cronbach alpha of SJT was .70 ), where higher scores indicated higher communication competence of the driver examiner. Exampleitem of the test and response options are provided in Annex 1.

The procedure of situational judgement test development in this study was analogous to the ones used in the literature (Jobtestprep, 2014; Mahesan, Choudhury, \& Rymer, 2012; Chamorro-Premuz- ic \& Furnham, 2010; Jackson, LoPilato, Hughes, Guenole, \& Shalfrooshan, 2017). Sixteen situations were generated at the beginning by the group of subject matter experts (SMEs) composed from psychologists and line managers of driver examiners. These situations were theoretically matched to communication psychology theory (Bedwell et al., 2011; Purhonen \& Valkonen, 2013) and job description of driver examiner. Then a set of testing trials was executed in the group of eight experienced psychologists in order to develop the scoring key for the developed SJT. Based on the input from SME (supervisors of driving examiners) and psychologists' ten situations were chosen for the final version of SJT that produced the sufficient level of expert consensus (agreement from 70 to 100 percent) and internal consistency (Jackson et al., 2017; Streiner, 2003; Nunnally \& Bernstein, 2004; Whetzel \& McDaniel, 2009). Also the pilot construct validity examination of the newly developed test was conducted in the different sample (university students) using Interpersonal Reactivity Index (Davis, 1980) intended to measure empathic concern and support for others. Correlation between two tests was .36 $(\mathrm{p}<.001)$ showing some construct validity of SJT. Whetzel $\&$ McDaniel (2009) argue that SJTs measure multiple constructs with the same items, therefore, their validity and reliability coefficients might not be high. Other well-established external construct measures are hardly available in Lithuania, therefore further validity studies of newly developed SJT in different samples are still under consideration.

Job performance evaluations of driver examiners were obtained from their supervisors, using the standardized procedure and 20-item questionnaire employed in the organization "Regitra". 10 supervisors had routinely rated their subordinates' work proficiency in five performance dimensions - communication (3 items, for example "showed respect to examinee"), preparation for the exam (4 items, for example "explained the procedure of the examination before the exam to the candidate clearly"), behaviour during exam (4 items, for example "observed the behaviour of examinee carefully", "evaluated the skills correctly"), feedback about performance in the exam provided to driving licence candidate (6 items, for example "provided positive as well as negative feedback"), filling of the exam protocol (3 items, for example "documents were filled according to instructions"). This procedure had been conducted in the institution on the regular basis (at least four times 
a year); supervisors rated their examiners through observation in a car during the actual examination session. Each dimension was scored on Likert type scale from " 1 - poor" to " 5 - very good". The mean score of the five recent evaluations on these work behaviours were provided to researchers, also the general sum score of job performance was used in the analyses. Additionally, the number of claims from clients during three previous years were provided to researchers.

\subsection{Procedure}

The organization managers informed the staff members about the upcoming study and assured the confidentiality of personal data. Coded job performance ratings of each driving examiner were provided to investigators from personnel files stored at the Human Resource Department of the organization. Examiners completed paper - pencil questionnaires that were provided personally by the member of investigation team. Each questionnaire was provided in the sealed envelope with the identification code used to match self-ratings with supervisor ratings. Oral informed consent was obtained from participants, with particular attention paid to the confidentiality and safety issues. The self - report data about personality traits, communication competence and attitudes of driving examiners were not provided to their super- visors. Only general report about study results was presented in oral and written form to the organization. As an incentive for participation each driving examiner got personal feedback about their results on personality, risk attitudes and communication competence scales.

\subsection{Statistical analysis}

Descriptive statistics and zero-order correlations were calculated in order to explore the sample characteristics as well as the relationships among study variables. Linear regression analyses were employed for testing the predictive validity of individual differences (personality, communication and attitudinal attributes) as independent variables for supervisorrated job performance of driving examiners. Twostep cluster analysis was used in order to explain the profile differences between more and less successful examiners.

\section{RESULTS}

Descriptive statistics of all variables analysed in this paper were presented in Table 1. Results revealed that supervisors in average evaluated the job performance of examiners very well. The overall scores of work effectiveness and its components were moved

Table 1: Descriptive statistics of job performance, personality traits, communication competence, and safety attitudes

\begin{tabular}{lcccc}
\hline Variable & Mean & SD & Minimal value & Maximal value \\
\hline JP: Communication & 4.51 & .48 & 3.4 & 5.0 \\
JP: Preparation for exam & 4.41 & .45 & 3.4 & 5.0 \\
JP: Behaviour during exam & 4.43 & .46 & 3.3 & 5.0 \\
JP: Feedback & 4.37 & .45 & 3.2 & 5.0 \\
JP: Filling the protocol & 4.49 & .44 & 3.2 & 5.0 \\
Overall JP & 22.22 & 1.77 & 18.0 & 25.0 \\
Number of claims during last 3 years & 2.17 & 2.18 & 0 & 13 \\
Neuroticism & 46.45 & 7.66 & 30.67 & 71.42 \\
Extraversion & 49.00 & 6.38 & 31.34 & 64.51 \\
Openness to experience & 46.02 & 8.36 & 27.90 & 67.26 \\
Agreeableness & 57.22 & 8.66 & 33.42 & 77.25 \\
Conscientiousness & 53.90 & 7.67 & 24.23 & 72.30 \\
Attitudes toward traffic safety & 33.23 & 8.32 & 18 & 53 \\
Communication competence & 5.58 & 2.49 & 0 & 10 \\
\hline
\end{tabular}


significantly towards their maximum value. Other variables, like personality traits, communication competence, and attitudes towards traffic safety had higher score variability.

Correlational analysis was performed using Spearmen's correlation coefficients. Data revealed that all components of job performance, except filling the exam protocol, were strongly related to each other and general score of job performance (Table 2). Variable "filling the protocol" had weak or moderate correlations with other indicators of job performance. Only few significant correlations among job performance dimensions and personality traits, communication skills, and safety attitudes were found. The overall score of work effectiveness correlated positively with the score of conscientiousness. This personality trait also was related to higher scores of communication and feedback delivery as indicators of work proficiency and lower number of received complaints. Neither other personality traits nor communication competence and safety attitudes were related to general score of job performance and its dimensions. Attitudes towards traffic safety were significantly positively correlated to neuroticism and negatively to agreeableness, conscientiousness, and communication competence. Education and work tenure was not significantly related to any analysed variable.

In order to control for possible confounding variables the regression analysis was conducted to predict overall score of job performance. The overall score was selected as dependent variable as it was strongly related with other indicators of job performance. The linear regression was applied due to normal distribution of the scores of dependent variable. Predictive variables were added into analysis in several blocks: first - educational level, second - all personality traits and safety attitudes, and lastly - communication competence. This model appeared to be non-significant $(\mathrm{F}=1.436 ; \mathrm{df}=8 ; \mathrm{p}=.196)$. Still, single blocks of variables added to the explanation of variance of job performance: first could explain 4 percent of variance, first and second -6.3 , and all three together - 13.1 percent. Although the conclusion cannot be drawn using non-significant model, some of variables were excluded in order to get better subjectvariable ratio in regression. Conscientiousness, communication competence, safety attitudes, and education remained as dependent variables; enter method was chosen (Table 3). Data showed that model could significantly add to the explanation of job perfor- mance of examiners $(\mathrm{F}=2.888 ; \mathrm{df}=4 ; \mathrm{p}=.027)$. Scores of predictor variables explained 12.6 percent of variance of work effectiveness. Only higher scores of communication competence explained better work performance, when education, conscientiousness, and safety attitudes were controlled.

In order to answer the question, how the best driving examiners could be described according to their psychological characteristics, two step cluster analysis with log-likelihood distance measure was performed. A two-cluster-solution was chosen. They allowed to identify different types of examiners based on work performance, personality traits, communication competence, and traffic safety attitudes. One cluster might be relatively named as poorer performers with significantly lower scores of work proficiency evaluation, lower scores of extraversion, conscientiousness, agreeableness, openness to experience, and higher neuroticism and risky attitudes to road behaviour. They constituted of 32.2 percent of the sample. Another group of examiners could be referred to better performers, who have significantly higher scores of work effectiveness evaluation, higher scores of extraversion, conscientiousness, agreeableness, openness to experience, and communication competence, lower scores of neuroticism, safer attitudes towards road behaviour. 67.8 percent of participants belonged to the second cluster. The centroids of both clusters differed significantly for all variables included in the analysis $(p<.05)$. Variable significance analysis revealed that traffic safety attitudes and conscientiousness had relatively higher contribution to each cluster.

The clusters differed in educational level of examiners $\left(\chi^{2}=6.444 ; d f=1 ; p=.019\right) .41 .2$ percent of the first cluster members (poorer performers) and 73.5 percent of the second cluster members (better performers) had a university degree.

\section{DISCUSSION}

Efficient work of driver examiners might be important for traffic safety although research on psychological and organizational factors related to their performance is lacking. This study was intended to contribute to the gap in the literature and to investigate the correlates of job success in this unique group of employees. It was aimed to evaluate the importance of examiners' individual characteristics (personality traits, communication competence, and risk taking 


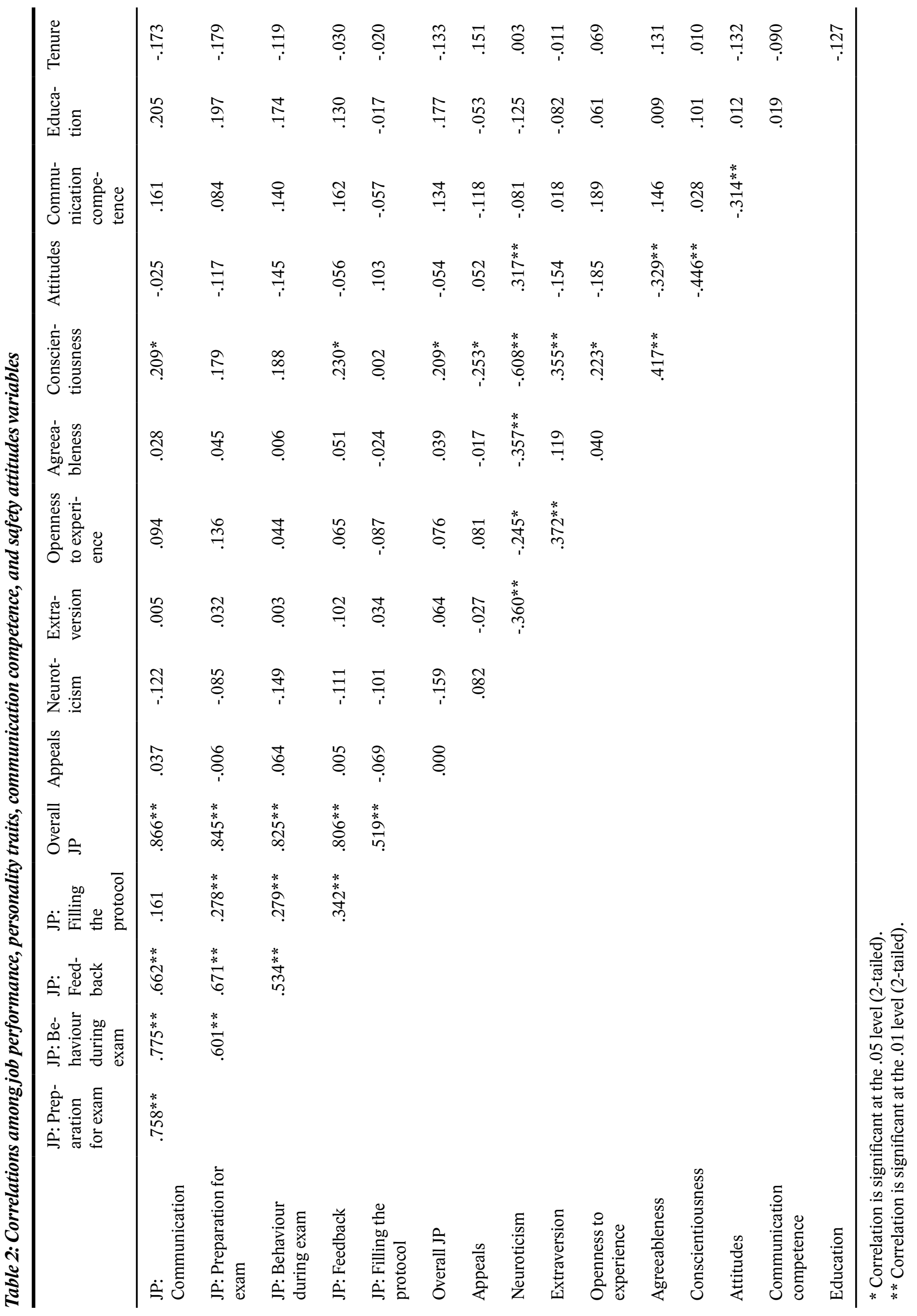


Table 3: Linear regression analysis used to predict job performance

\begin{tabular}{lrcccc}
\hline & B & Std. Error & Beta & t & Significance \\
\hline Constant & 17.081 & 2.179 & & 7.838 & .000 \\
Education & .597 & .486 & .135 & 1.227 & .223 \\
Conscientiousness & .032 & .027 & .137 & 1.170 & .245 \\
Communication competence & .268 & .102 & .296 & 2.625 & .010 \\
Safety attitudes & .018 & .026 & .084 & .700 & .486 \\
\hline
\end{tabular}

Table 4: Cluster centroids of personality traits, communication competency, and safety attitudes for two clusters

\begin{tabular}{lllrrrrrrrr}
\hline & & $\begin{array}{l}\text { Job } \\
\text { Performance }\end{array}$ & $\begin{array}{l}\text { Neurot- } \\
\text { icism }\end{array}$ & $\begin{array}{l}\text { Extra- } \\
\text { version }\end{array}$ & $\begin{array}{l}\text { Openness to } \\
\text { experience }\end{array}$ & $\begin{array}{l}\text { Agreea- } \\
\text { bleness }\end{array}$ & $\begin{array}{l}\text { Conscien- } \\
\text { tiousness }\end{array}$ & $\begin{array}{l}\text { Communication } \\
\text { competence }\end{array}$ & Attitudes \\
\hline 1 cluster & Mean & 21.30 & 52.40 & 46.63 & 43.48 & 51.31 & 47.43 & 5.18 & 41.36 \\
& SD & 1.70 & 8.40 & 8.34 & 7.50 & 8.50 & 8.14 & 2.28 & 6.31 \\
2 cluster & Mean & 22.45 & 43.82 & 50.36 & 47.78 & 59.33 & 55.96 & 6.47 & 30.07 \\
& SD & 1.70 & 5.96 & 5.19 & 7.97 & 7.53 & 5.53 & 1.65 & 6.42 \\
& $\mathrm{t}$ & -2.931 & 4.854 & -2.179 & -2.399 & -4.449 & -5.738 & -3.012 & 7.701 \\
& $\mathrm{df}$ & 85 & 40.361 & 37.258 & 85 & 85 & 85 & 85 & 85 \\
& $\mathrm{p}$ & .004 & .000 & .036 & .019 & .000 & .000 & .003 & .000 \\
\hline
\end{tabular}

attitudes on the road) for the prediction of their job proficiency.

Based on the results it could be concluded that all measured individual factors (Big Five personality traits, attitudes, and communication competence) can be modestly useful for identification which driving examiners perform better. It was found that slightly better performers are those who have personality traits leading to better adjustment in general, i.e. higher conscientiousness, agreeableness, openness to experience, extraversion and lower neuroticism as though as high communication competence and more positive attitude towards traffic safety. Such employee personality profile is similar to ones described in other studies (Forero, Gallardo-Pujol, Maydeu-Olivares, \& Andres-Pueyo, 2009; Huang, Ryan, Zabel, \& Palmer, 2014; Teodorescu et al., 2017; Weldon et al., 2017). Our study supported previous data in other occupational groups and confirmed that attributes underlying broad traits, like achievement orientation, impulse control, sociability, dutifulness, emotional coping skills etc., become intrinsic motivators of proper work behaviour and better task accomplishment (Joseph et al., 2015; Huang et al., 2014).

Variable-oriented approach based on the correlational analysis of data also let to draw the con- clusion that conscientiousness could be treated as the strongest correlate of examiners' performance. These results confirm previously established relations between this trait and work outcomes across diverse occupations (Lang et al., 2012; Neal et al., 2012; Sjöberg et al., 2012; Teodorescu et al., 2017). As a person with high conscientiousness could be described as one who is able to set goals, self-motivate, be persistent along with striving for achievements, and being ethical (Costa \& McCrae, 1998), he or she functions better in organizational settings (Joseph et al., 2015; Judge, Rodell, Klinger, Simon, \& Crawford, 2013). Despite this, the association between conscientiousness and overall job performance ratings was weak in examiners' sample. Homogenous group and broad trait measurement strategy might be responsible for such finding. Judge et al. (2013) argued that more significant relations among personality traits and job performance measures might be found if narrower constructs (facets) and specific contextual measures of job performance would be used. Also, the ratings of the examiners' job performance tended to be on the higher end in this study, justifying the assumption that examiners with poorer abilities have already been fired or quitted the job. Low variability in job performance ratings might lead to less inform- 
ative correlations between individual differences and job performance.

Our findings revealed that taking into consideration other important individual attributes (level of education, traffic safety attitudes, and conscientiousness), communication competence was the only significant predictor of better job performance of driver examiners. These results are in line with the previous findings showing that better communication skills predict more effective employee performance in different occupations (managers, health professionals, police officers, teachers, etc.), especially in these where social interactions sustain the important part of work behaviour (Bedwell et al., 2011; Spitzberg, 2013; Riggio, Riggio, Salinas, \& Cole, 2003; Forero et al., 2009). The results of current study confirm that conflict resolution skills, flexibility, showing support and coping with stress help driver examiners to perform well at work.

However the modest explanatory role of individual differences (12.6 percent of the job performance variance explained by personality measures, communication competence, and attitudes) encourage to look for further explanations. Such a finding might be the result of methodological issues, as driver examiners of this study composed quite a homogenous group according to their work tenure and supervisorrated job proficiency. Low variation in these measures suspended from revealing of the true role of individual differences. On the other hand, the results indicate that psychological characteristics may lose their importance for work success with longer experience. Acquiring profound job knowledge and learning to fulfil the most important job tasks become more important contributors of success than personality attributes (Gerhardt, Ashenbaum, \& Newman., 2009). Our study does not provide the clear answer what accounts more for efficient work of driver examiners - successful selection and recruitment procedures or formal and informal learning at the workplace. Longitudinal study using predictive research design (where driving examiners would be tested before their employment and after some time of working) would provide more robust conclusions about the role of individual differences for job performance in this occupational group.

Also it should be noted that the current study did not investigate the contribution of driver examiners' work behaviour to traffic safety issues. The rationale for the research was based on the assumption that distal relationship between effective examining pro- cedures and proper driving behaviour after this procedure exists. Some attempts have been made to test validity of the driving test and later crash involvement (Baughan \& Sexton, 2002; Baughan, Sexton, Simpson, Chinn, \& Quimby, 2006), still the results are scarce and contradictory. Thus, more direct investigations of the driving examiners occupational behaviour and later accident rates of their examinees would be beneficial implication for future research.

\section{Limitations}

Several limitations had to be taken into account when applying the results of the current study. One of these is rather a small number of participants employed in the study. Although, the participants' number reflected the ecological validity (about 90 percent of all driving examiners in Lithuania took part in the study), more sophisticated statistics couldn't be applied or models did not have enough power to show statistical significance.

The current study shared obvious methodological strength because it involved different sources of data as examiners responded about themselves and were evaluated by their supervisors. So, the results could not be affected by common method variance. Despite this, job performance ratings from supervisors were collected as a part of routine evaluation of examiners' work activities. There was no information how these evaluations were standardised among supervisors, what criteria they used to assess job performance of employees. Multilevel analysis which could take into account differences among supervisors might be helpful; still participants' number was insufficient for such analysis.

Also some concerns might be related to the instrument of job performance appraisal. The questionnaire was developed to assess the task (objective skill evaluation) as well as contextual performance of the employee (social and organizational aspects in functioning as an employee) (Borman \& Motowildo, 1997). Hence, the item analysis raises the assumptions that contextual performance is covered more than task performance. Therefore, the further improvements of the instrument are encouraged as the practical implication for the organization as well as future research implication.

Job performance measurement might have been sensitive to selection bias in this study, as supervisors' ratings were tended to be on the higher end. More problematic and less efficient driving examin- 
ers might be absent from the sample as they already are not employed. Low variability of job performance is quite common issue in the selection literature when the concurrent validity strategy for job performance prediction is used (Chamorro-Premuzic \& Furnham, 2010). Therefore, the results should be applied with some cautiousness and long-term studies with predictive validity approach are welcome in future research. Further studies are encouraged to follow up a group of newly recruited examiners during their first year and monitor if the conclusions from the current study could be of use for these new group. Such results would provide more robust data about the selection of these specialists.

Self-reported data collected from examiners should be considered as limitation as well. Participants of the study were surveyed at their workplaces. It is a common practice in organizational psychology research to administrate the survey at the institution, where respondents work (Teodorescu et al., 2017; Neal et al., 2012; Weldon et al., 2017). Despite the efforts of researchers to warrant confidentiality, examiners could feel pressure and might present themselves in a more favourable manner.

Finally, the situational judgment test to measure communication competence of examiners was created by the authors for the purpose of this study. It hasn't undergone thorough examination of validity yet. Previous research did not introduce sound and valid measurements of communication skills based on situational judgement. Usually, researchers create their own instruments of situational judgement test with minimal attention of its validity (Lievens $\&$ Sackett, 2012; Mahesan et al., 2012). The measurement of communication competence in this study showed acceptable internal consistency among items, and it was a significant predictor of job performance. Still, further validation efforts of the test are necessary.

\section{Implications}

The results of the current study might be important for personnel selection and recruitment as well as for traffic safety specialists. Research data allowed to distinguish the psychological characteristics of group of examiners who were evaluated as performing better at their work. It could be suggested that those characteristics that differentiated two groups of driving examiners might be in the focus during the selection procedure. Authors of this study propose to address personality traits with higher attention to conscientiousness, communicational skills, and attitudes towards traffic safety, while selecting driving examiners. As personality traits are referred to individual characteristics which are difficult to change they definitely are the matter of recruitment. In cases when the complete process of driving examiner candidate selection is unavailable assessment of communication skills would be still useful.

Communication efficiency and safety attitudes could be influenced during learning or typical socialization at work. Previous authors suggest that in order to ensure job effectiveness communication skills should be both addressed during recruitment and strengthened with further occupational training (Lievens \& Sackett, 2012). Attitudes towards risk behaviour of driving examiners should be continually discussed as a part of organizational culture and safety climate. Activities aiming to strengthen examiners intolerance for risk taking on the road could be employed in order to ensure more outstanding work role performance of examiners.

\section{REFERENCES}

Barrick, M. R., Mount, M. K., \& Judge, T. A. (2001). Personality and performance at the beginning of the new millennium: What do we know and where do we go next? International Journal of Selection and Assessment, 9(1-2), 9-30.

Baughan, C. \& Sexton, B. F. (2002). Do driving test errors predict accidents? : yes and no. In Grayson, G. B. (Ed.), Behavioural research in road safety XI: proceedings of the 11th seminar on behavioural research in road safety, Crowthorne: Transportation Research Laboratory TRL, 252-268.

Baughan, C., Sexton, B., Simpson, H. M., Chinn, l. \& Quimby, A. R. (2006), Novice driver safety and the British practical driving test (TRL652). Crowthorne: Transportation Research Laboratory TRL. http://trl.demo.varistha.co.uk/uploads/trl/documents/TRL652.pdf.

Bedwell, W. L., Fiore, S. M., \& Salas, E. (2011). Developing the 21 st Century (and Beyond) Workforce: A Review of Interpersonal Skills \& Measurement Strategies. In National Research Council: Assessment of 21st Century Skills. Washington, DC: The National Academies.

Beshai, S., Prentice, J. L., Swan, J. L., \& Dobson, K. S. (2015). The effects of dysphoria and personality on negative self-referent attitudes and perceptions of the attitudes of others. The Journal of Psychology, 149(5), 498-516.

Bilgiç, R. \& Sümer, H. C. (2009). Predicting military performance from specific personality measures: A validity study. International Journal of Selection and Assessment, 17(2), 231-238. 
Borman, W. C. \& Motowidlo, S. J. (1997). Task Performance and Contextual Performance: The Meaning for Personnel Selection Research. Human Performance, 10(2), 99-109.

Carraher, S. M. (2011). Turnover prediction using attitudes towards benefits, pay, and pay satisfaction among employees and entrepreneurs in Estonia, Latvia, and Lithuania. Baltic Journal of Management, 6(1), 25-52.

Chamorro-Premuzic, T. \& Furnham, A. (2010). The Psychology of Personnel Selection. Cambridge University Press.

Costa, P. T., \& McCrae, R. R. (1992). Four ways five factors are basic. Personality and Individual Differences, 13(6), 653-665.

Costa, P.T. \& McCrae, R.R. (1998). Six approaches to the explication of facet-level traits: examples from conscientiousness. European Journal of Personality, 12, 117-134.

Davis, M. H. (1980). A multidimensional approach to individual differences in empathy. JSAS Catalog of Selected Documents in Psychology, 10, 85. https://www.uv.es/friasnav/Davis_1980.pdf.

Driver and Vehicle Standards Agency, DVSA (2017). https:// www.gov.uk/government/organisations/driver-and-vehiclestandards-agency.

Forero, C.G., Gallardo-Pujol, D., Maydeu-Olivares, A., \& Andres-Pueyo, A. (2009). A longitudinal model for predicting performance of police officers using personality and behavioural data. Criminal Justice and Behaviour, 36 (6), 591-606.

Gerhardt, M., Ashenbaum, B., \& Newman, W. R. (2009). Understanding the impact of proactive personality on job performance: the roles of tenure and self-management. Journal of Leadership \& Organizational Studies, 16(1), 61-72.

Gilar, R., de Haro, J. M., \& Castejon, J. L. (2015). Individual differences in predicting occupational success: the effect of population heterogeneity. Revista de Psicología del Trabajo y de las Organizaciones, 31(2), 101-107.

Hashimoto, M., Andreassi, T., Nakata, L. E., \& Artes, R. (2016, January). Is Job Satisfaction Enough? Entrepreneurial Orientation vs Internal Climate Effects on Performance. In Academy of Management Proceedings, 1, 10971. Academy of Management.

Higgins, D.M., Peterson, J.B., Pihl, R.O., \& Lee, A.G.M. (2007). Prefrontal Cognitive Ability, Intelligence, Big Five Personality, and the Prediction of Advanced Academic and Workplace Performance. Journal of Personality and Social Psychology, 93, 298-319.

Huang, J. L., Ryan, A. M., Zabel, K. L., \& Palmer, A. (2014). Personality and adaptive performance at work: A meta-analytic investigation. Journal of Applied Psychology, 99(1), 162-179.

International commission for driver testing CIECA. (2017). http://www.cieca.eu/.

Iversen, H. \& Rundmo, T. (2004). Attitudes towards traffic safety, driving behaviour and accident involvement among Norwegian public. Ergonomics, 47, (5), 555-572.

Jaakson, K., Vadi, M. \& Baumane-Vìtolin, I. (2018). The effect of negative work outcomes and values on the perceived likelihood of employee dishonest behaviour. Baltic Journal of Management, 13, 4, 605-622.
Jackson, D. J., LoPilato, A. C., Hughes, D., Guenole, N., \& Shalfrooshan, A. (2017). The internal structure of situational judgement tests reflects candidate main effects: Not dimensions or situations. Journal of Occupational and Organizational Psychology, 90(1), 1-27.

Jobtestprep (2014). Free situational judgment test questions. https://www.jobtestprep.co.uk/. Accessed in November 10, 2015.

Joseph, D. L., Jin, J., Newman, D. A., \& O’Boyle, E. H. (2015). Why does self-reported emotional intelligence predict job performance? A meta-analytic investigation of mixed EI. Journal of Applied Psychology, 100, 2, 298-342.

Judge, T. A., Rodell, J. B., Klinger, R. L., Simon, L. S., \& Crawford E. R. (2013). Hierarchical representations of the FiveFactor Model of Personality in predicting job performance: integrating three organizing frameworks with two theoretical perspectives. Journal of Applied Psychology, 98 (6), 875-925.

Judge, T. A. \& Zapata, C. P. (2014). The Person-Situation Debate Revisited: Effect of Situation Strength and Trait Activation on the Validity of the Big Five Personality Traits in Predicting Job Performance. Academy of Management Journal, 58, 4, 1149-1179.

Lang, J.W.B., Zettler, I., Ewen, C., \& Hulsheger, U.R. (2012). Implicit motives, explicit traits, and task and contextual performance at work. Journal Applied Psychology, 97, 1201-1217.

Lazauskaite-Zabielske, J., Urbanaviciute, I. \& Rekasiute Balsiene, R. (2018). From psychosocial working environment to good performance: the role of work engagement. Baltic Journal of Management, 13(2), 236-249.

Lievens, F. \& Sackett, P.R. (2012). The validity of interpersonal skills assessment via situational judgment tests for predicting academic success and job performance. Journal of Applied Psychology, 97(2), 460-468.

Mahesan N., Choudhury S.M., \& Rymer J. (2012). Get ahead! The situational judgment test. NW: Taylor \& Francis.

Neal, A., Yeo G., Koy, A., \& Xiao, T. (2012). Predicting the form and direction of workrole performance from the Big 5 model of personality traits. Journal of Organizational Behavior, 33, 175-192.

NEO PI-R. Taisyto NEO asmenybès ir NEO penkiu faktoriu klausimynu vadovas (2012), [NEO PI - R User Manual]. Bagdonas, A. and Kairys, A. (Eds.): Vilnius: VU Specialiosios psichologijos laboratorija.

Nunnally, J. C. \& Bernstein, I. H. (1994). Psychological theory. New York, NY: MacGraw-Hill.

Ones, D.S., Dilchert, S., Viswesvaran, C., \& Judge, T.A. (2007). In Support of Personality Assessment in Organizational Settings. Personnel Psychology, 60 (10), 995-1027.

Parkes, K. R., Anastiasades, P., Broadbent, D. E., Johnston, O., Rendall, D., Matthews, J., \& Smith, A. P. (1986). Occupational Stress among Driving Examiners: A Study of the Effects of Work Load Reduction. Final Report and Recommendations. Prepared under HSE Commission, 1/MC/126/158/79. Department of Experimental Psychology, University of Oxford. 
Perugini, M., Zogmaister, C., Richetin, J., Prestwich, A., \& Hurling, R. (2013). Changing implicit attitudes by contrasting the self with others. Social Cognition, 31(4), 443-464.

Purhonen, P. \& Valkonen, T. (2013). Measuring interpersonal communication competence in SME internationalization. Journal of Intercultural Communication, (33). http://immi.se/intercultural/nr33/purhonen.html.

Riggio, R.E., Riggio, H.R., Salinas, C. \& Cole, E.J. (2003). The role of social and emotional communication skills in leader emergence and effectiveness. Group Dynamics: Theory, Research, and Practice, 7(2), 83-103.

Rode, J.C., Mooney, Ch.h., Arthaud-Day, M.L., Near, J.P., Baldwin, T.T., Rubin, R.S., \& Bommer, W.H. (2006). Emotional intelligence and individual performance: evidence of direct and moderated effects. Journal of Organizational Behavior, 28 (4), 399-421.

Rothstein, M. G. \& Goffin, R. D. (2006). The use of personality measures in personnel selection: What does current research support? Human Resource Management Review, 16(2), 155-180.

Salanova, M., Llorens, S., \& Schaufeli, W. B. (2011). "Yes, I can, I feel good, and I just do it!" On gain cycles and spirals of efficacy beliefs, affect, and engagement. Applied Psychology, 60(2), 255-285.

Schmitt, N. (2014). Personality and cognitive ability as predictors of effective performance at work. Annu. Rev. Organ. Psychol. Organ. Behav., 1(1), 45-65.

Schrock, W. A., Hughes, D. E., Fu, F. Q., Richards, K. A., \& Jones, E. (2016). Better together: Trait competitiveness and competitive psychological climate as antecedents of salesperson organizational commitment and sales performance. Marketing Letters, 27(2), 351-360.

Sjöberg, S., Sjöberg, A., Näswall, K., \& Sverke, M. (2012). Using individual differences to predict job performance: Correcting for direct and indirect range restriction. Journal of Scandinavian Psychology, 53, 368-373.

Spitzberg, B.H. (2013). (Re)Introducing communication competence to the health professions. Journal of Public Health Research, 2:23, 126-135.

Streiner, D. L. (2003). Starting at the beginning: an introduction to coefficient alpha and internal consistency. Journal of Personality Assessment, 80(1), 99-103.

Teodorescu, A., Furnham, A., \& MacRae, I. (2017). Trait correlates of success at work. International Journal of Selection and Assessment, 25(1), 36-42.

Twisk, D. A., \& Stacey, C. (2007). Trends in young driver risk and countermeasures in European countries. Journal of Safety Research, 38(2), 245-257.

United Nations (2015). Transforming our World: The 2030 Agenda for Sustainable Development. https://sustainabledevelopment.un.org/post2015/transformingourworld/publication.

Weldon, P. T., Fletcher, C., \& MacIver, R. (2017). The predictive validity of individual psychological assessments in selecting UK public sector senior managers. International Journal of Selection and Assessment, 25(1), 11-17.
Whetzel, D.L. \& McDaniel, M.A. (2009). Situational judgment tests: an overview of current research. Human resource management review, 19, 188-202.

World Health Organization (WHO). Global Status Report on Road Safety. 2018. Available at: https://www.who.int/violence injury_prevention/road_safety_status/2018/en/.

Zhong, L., Wayne, S. J., \& Liden, R. C. (2016). Job engagement, perceived organizational support, high-performance human resource practices, and cultural value orientations: A cross-level investigation. Journal of Organizational Behavior, $37(6), 823-844$.

\section{ANNEX 1. EXAMPLE-ITEM OF SITUATIONAL JUDGEMENT TEST AND RESPONSE OPTIONS}

You have been working in the current organization for six months together with three colleagues. You and your colleagues already know each other quite well and have settled friendly relationships. Recently you noticed that one of your colleagues has changed and looks like something has happened to him. Also accidentally you have heard how your supervisor complained to someone about poor work performance of this colleague. What are you going to do?

A You invite your colleague for a cup of coffee and express your worry because of his state.

B You tell your colleague that he is performing not well at the moment and suggest to help to do his work.

C You will monitor your colleague for several days and will try to work together with him as much as possible.

D You tell to your supervisor that you have heard his talk about your colleague and express your worry about the state of colleague to your supervisor.

E You share your worries to all other colleagues and try to find the solution together. 